rev.relac.int.estrateg.segur.8(1):267-278,2013

\title{
LOS ORÍGENES DE LA COOPERACION INTERNACIONAL EN MATERIA DE TERRORISMO. LAS PRIMERAS RESPUESTAS INTERNACIONALES*
}

\author{
Luis Ángel Aparicio-Ordás González-García**
}

\section{RESUMEN}

El nacimiento de un nuevo fenómeno de violencia y de terror, distinto a cualquier otro fenómeno histórico de violencia ha obligado desde sus orígenes a la Comunidad Internacional a desarrollar una serie de instrumentos legales ante el problema común del terrorismo.En este trabajo analizaremos los orígenes de la cooperación internacional en materia de terrorismo y cómo la Comunidad Internacional se ha visto obligada a dar una respuesta en diversos momentos históricos ante la amenaza de fenómenos basados en la violencia y el terror.

Palabras clave: Anarquismo, terrorismo, conflicto, violencia.

* Este trabajo recoge algunas de las reflexiones contenidas en mi Tesis Doctoral titulada "Enfrentamientos asimétricos, la respuesta del Estado español frente a la amenaza del terrorismo. Asimetría y Simetría en el conflicto", defendida el 14 de septiembre del año 2012 en la Universidad Alfonso X el Sabio de Madrid (España) y que obtuvo la máxima calificación académica de la Facultad de Ciencias Sociales y Jurídicas de la UAX.

** Doctor en Derecho Político por la Universidad Alfonso X el Sabio de Madrid (España). Especialista e investigador en materia de Seguridad y Terrorismo. Publica sus trabajos de investigación en el International Relations BergInstitute, en el Centro Superior de Estudios de la Defensa Nacional (CESEDEN) y del Instituto Español de Estudios Estratégicos (IEEE) (Madrid, España). Ámbito de Investigación: conflictos asimétricos, amenazas emergentes. Diseño de estrategias de control de riesgos (ECR). Elabora indicadores del fenómeno terrorista para evaluar futuras oleadas de actividad terrorista. aparicioordas@gmail.com 


\title{
THE BEGINNING OF INTERNATIONAL COOPERATION IN THE PRESENCE OF TERRORISM: THE INITIAL INTERNATIONAL RESPONSES
}

\begin{abstract}
The appearance of a new phenomenon of violence and terror, different from any other aggressive episode in history, has forced the International Community to develop from the beginning several legal instruments to confront the broad problem of terrorism. In this article, we shall analyze the origins of international cooperation in the matter of terrorism and how the International Community has been forced, in a number of historical moments, to respond to the threats of phenomena based in violence and terror.
\end{abstract}

Key words: Anarchism, terrorism, conflict, violence.

\section{AS ORIGENS DA COOPERAÇÃO INTERNACIONAL SOBRE TERRORISMO: AS PRIMEIRAS RESPOSTAS INTERNACIONAIS}

\section{RESUMO}

O nascimento de um novo fenômeno de violência e de terror, ao contrário de qualquer outro fenômeno histórico de violência, vem obrigando desde suas origens a Comunidade Internacional para desenvolver uma série de instrumentos legais perante o problema comum de terrorismo. Neste artigo, analisaremos as origens da cooperação internacional contra o terrorismo e como a Comunidade Internacional tem sido forçada a responder em diferentes momentos históricos diante da ameaça dos fenômenos sustentados na violência e terror.

Palavras-chave: anarquismo, terrorismo, conflito, violência.

\section{INTRODUCCIÓN}

La gravedad y la proliferación de los atentados terroristas que van a sufrir diversos países a finales del siglo XIX serán de tal magnitud, que la Comunidad Internacional se verá en la necesidad de abordar el fenómeno de la violencia terrorista. Así, aparecerán los dos primeros instrumentos legales de carácter internacional para enfrentar la amenaza terrorista. La primera aparecerá en el año 1898 con la Conferencia de Roma de noviembre de ese año y la segunda en el año 1937 con la Conferencia para la Represión Internacional del Terrorismo de Ginebra, en el marco de la entonces Sociedad de Naciones, siendo los primeros instrumentos jurídicos en la historia con vocación internacional, dando la Comunidad Internacional, sus primeros pasos hacia la adopción de una serie de medidas para enfrentar el problema común del terrorismo internacional. 
En la actualidad la regulación jurídica de esta materia, es el resultado de un proceso cuyos comienzos podemos situar específicamente en el año 1937. Después de la Segunda Guerra Mundial, se producirá un importante impulso, donde una la ingente producción legislativa tendrá como objetivo combatir y erradicar el terrorismo, vinculando este esfuerzo al trabajo realizado en el seno de diversas Organizaciones internacionales, de las que procederá la mayor parte de la regulación que se viene elaborando en materia de terrorismo.

El terrorismo aparecerá desde entonces estrechamente vinculado en su análisis jurídico, a los propósitos centrales de la Comunidad Internacional y a los principios fundamentales del ordenamiento jurídico internacional. Para enfrentar el problema del terrorismo es necesario reflexionar, en torno al mantenimiento de la paz y la seguridad internacionales, introduciendo el análisis, principios como la protección internacional de los derechos humanos, el no uso de la fuerza en las relaciones internacionales y la cooperación internacional.

\section{LA CONFERENCIA DE ROMA DEL AÑO 1898}

A finales del siglo XIX y principios del siglo XX irrumpe un ideal revolucionario y transformador,que va a servir de inspiración a pequeños grupos de ideología anarquista y que van a ser los protagonistas de una serie de atentados de gran transcendencia que tendrán principalmente como objetivo, en la considerada primera oleada de terrorismo moderno,los actores del poder político de la época: Jefes de Estado y de Gobierno (Avilés y Herrerin, 2008, p. IX). El asesinato político así, será un ataque al centro de gravedad del poder gubernamental. La fuerza de esta estrategia es tal, que provocará una sacudida y una paralización en todo el sistema político estatal. La repercusión de los atentados será enorme y efectiva (Rapoport 2006, p. 10).

La geografía de esta oleada de actividad terrorista es asombrosa. Los atentados se sucedían en un orden regular. Durante 20 años de actividad terrorista de naturaleza anarquista, serán asesinados más Jefes de Estado y más Presidentes de Gobierno o Primeros Ministros que antes o después en la historia(Rapoport 2006, p. 10). Para Avilés y Herrerin (2008, p. IX),

[...] En todas partes un mismo ideal revolucionario empujaba hacia la violencia a los anarquistas, que leían a los mismos autores, se carteaban entre sí y se desplazaban a través de las fronteras. En aras de la revolución mundial había incluso militantes dispuestos a matar y morir fuera de su país [...].

Cabe recordar los asesinatos del Presidente francés Carnot en el año 1894, de la Emperatriz Isabel de Austria en el año 1898, del Rey Humberto I de Italia en el año 1900, el asesinato en el año 1901 del Presidente de Estados Unidos McKinley, o la bomba lanzada en la Cámara de 
Diputados de París en el año 1894. En España, el día 25 de octubre del año 1878, se produce el primer atentado contra el Rey Alfonso XIII; el día 30 de diciembre del año 1879 se producirá el segundo intento de atentar contra Alfonso XIII y su esposa; el día 31 de mayo de mayo del año 1905, se produjo un tercer atentado fallido contra Alfonso XIII en París y el día 31 de mayo de 1906 se producirá el cuarto intento de asesinato del Rey Alfonso XIII en Madrid el día de su boda. El terrorismo de naturaleza anarquista fue responsable de los asesinatos de los Presidentes del Gobierno de España Antonio Cánovas del Castillo, el 8 de agosto del año 1897, o de José Canalejas el 12 de noviembre del año 1912². Como destaca Rappoport, (2006, p. 1),

Si los dignatarios viajaban al extranjero, eran atacados a veces por los nativos de los países visitados. Por ejemplo cuando el Príncipe de Gales visitó Bruselas, un belga intentó asesinarle por la guerra de Gran Bretaña contra los Boers en Sudáfrica. Así mismo, cuando el Shah de Persia visitó París, un anarquista francés intentó perpetrar su asesinato.

La etiología de este fenómeno de violencia, que se va a propagar rápidamente por la mayoría de países europeos y por los Estados Unidos, la encontramos en una serie de elementos interrelacionados: la represión de el movimiento obrero, la actitud de las autoridades de los diversos países frente a los abusos de los empresarios que será la de reprimir a los trabajadores, y lo que es más importante: el cierre del sistema político al movimiento obrero impidiendo su entrada en el mismo y la represión a sus organizaciones y órganos de expresión. Así, el recurso al terrorismo constituirá un intento de una minoría del movimiento anarquista para romper el aislamiento político que impedía la participación del movimiento obrero en el sistema político de la época.

El carácter global de los atentados anarquistas era asombroso. La preocupación e inquietud fue de tal magnitud queel día 24 de noviembre del año 1898 se celebrará en Roma fruto del impulso del Gobierno Italiano una Conferencia Internacional "antianarquista". Fue Italia, que presionada por Viena y Berlín, convocó el 29 de septiembre del año 1898 la Conferencia de Roma con el objetivo de afrontar el terrorismo anarquista (Morán Blanco, 2010, p. 256).

1. Los atentados terroristas de naturaleza anarquista en España fueron múltiples y de una significación y repercusión enormes; así podemos citar: 1 de septiembre de 1886, bomba en la sede de la organización patronal Fomento de la Producción en Barcelona; 17 de enero de 1889, bomba en la casa de los fabricantes Batlló en Barcelona; 4 de mayo 1890, nueva bomba en la sede de Fomento de la Producción Nacional de Barcelona; 3 de mayo de 1891, Se localizan tres bombas en la Alameda de Cádiz; 9 de febrero de 1892, petardo en la Plaza Real de Barcelona ocasionando un muerto; 24 de septiembre de 1893 bomba contra el general Arsenio Martínez-Campos, Martínez Campos sólo fue ligeramente herido pero con el resultado de dos muertos y varios heridos; 7 de noviembre de 1893, lanzamiento de una bomba en el patio de butacas del Teatro del Liceo de Barcelona: veinte muertos y varios heridos; 25 de enero de 1894 atentado contra el gobernador civil, Ramón Larroca, que sufrió heridas de escasa consideración; 7 de junio de 1896, bomba en la calle de CanvisNous de Barcelona al paso de la procesión del Corpus Christi: doce muertos y sesenta heridos. 
La reunión se preparó desde el día 29 de septiembre de ese año, por el General Pelloux y el Ministro de Exteriores italiano Napoleone Canevaro, y tuvo lugar en la "Accademia dei Lincei" del Palacio Corsini de Roma, y convocará a 54 delegados (entre diplomáticos, altos cargos, funcionarios y mandos policiales) de 21 países entre los días 24 de noviembre y 21 de diciembre de 1898. La Cooperación internacional en materia de terrorismo había comenzado.

Las sesiones se celebraron en diversas Comisiones: por un lado entre funcionarios de policía cuyo objetivo era examinar las cuestiones técnicas y por otro, entre expertos judiciales que se encargaban de las posibles modificaciones legislativas, para que finalmente los representantes de los países condensasen en la Asamblea General los frutos de los debates de estas dos Comisiones.

La Comisión de juristas abordó los temas de la relación del anarquismo con el Derecho común, intentó determinar si los delitos cometidos por los anarquistas estaban comprendidos en los tratados de extradición, se analizó cómo establecer los medios de represión más adecuados que deberían adoptarse, así como medidas para impedir la circulación de la propaganda libertaria. Así mismo se estudió la creación de una policía internacional para perseguir al anarquismo.

No se llegó a un acuerdo sobre establecer una definición penal del anarquismo como doctrina que perseguía "la destrucción por medios violentos de toda organización social", una fórmula vaga que contó con el rechazo de varios países. En contra de las expectativas del gobierno italiano la Conferencia finalizó sin un acuerdo sobre la tipificación de "delito anarquista" y su tratamiento policial y jurídico.

La Conferencia finalmente se limitará a hacer recomendaciones a cada uno de los Estados participantes. Entre estas recomendaciones las más interesantes fueron: impulsar medidas legislativas contra la violencia anarquista; ofrecer una respuesta a la preparación de actos de violencia especialmente mediante explosivos, la incitación, la apología y la propaganda; la adopción de medidas legislativas contra la propaganda anarquista en el Ejército y el estudio de la posible aplicación de la pena de muerte para los autores de asesinatos de Soberanos y Jefes de Estado. En cuanto a la extradición de anarquistas, los delegados llegaron a un acuerdo por el que los crímenes anarquistas no deberían ser considerados crímenes políticos y que los actos violentos, como la fabricación de bombas, se determinasen como delitos por lo que se pudiera conceder la extradición.En el capítulo de la coordinación internacional, se estableció que las autoridades de los distintos países intercambiasen toda información posible, y que los anarquistas extranjeros expulsados de un país fueran enviados a su país de origen.

Los efectos prácticos de la Conferencia fueron muy limitados, estableciéndose una serie de compromisos en lugar de acuerdos concretos de cooperación. Se llegó por ejemplo al 
compromiso de establecer una coordinación entre la policía de los diferentes países, que no se produjo salvo en algún caso aislado, debido a las limitaciones que tenían las diversas policías y a su escasa preparación para hacer frente a este tipo de delitos. El protocolo final de la Conferencia de Roma fue firmado en el mes de julio del año 1889.

La Conferencia de Roma, constituye el primer paso hacia una coordinación internacional jurídico-policial y pese a sus exiguos resultados, será el primer instrumento de cooperación internacional, la primera respuesta unitaria de los Estados con el objetivo de aunar esfuerzos en la lucha antiterrorista.Fue el primer esfuerzo de la Comunidad Internacional para la construcción de un espacio de seguridad en Europa. El impulso de la Conferencia de Roma tendrá como consecuencia la creación de otros campos de cooperación regional como fue el Protocolo Antianarquista de San Petersburgo del año 1904.

En el año 1901 será asesinado el Presidente de los Estados Unidos, McKinley. ${ }^{2}$ El impacto producido por este asesinato, tendrá importantes repercusiones tanto dentro como fuera de los Estados Unidos. En los Estados Unidos, se comenzará a promulgar una legislación específica para dar respuesta a este tipo de actos de violencia ${ }^{3}$.

El asesinato del Presidente William McKinley, producirá también una reacción en Europa, iniciándose un nuevo esfuerzo diplomático (Morán Blanco, 2010, p. 259), así, el Gobierno ruso, solicitará que se retome el programa de la Conferencia de Roma. A esta iniciativa se sumará el Gobierno alemán, y el día 14 de marzo del año 1904 se firmará por los representantes de diez países europeos ${ }^{4}$ el Protocolo de San Petersburgo, que va a representar el primer acuerdo de coordinación policial de alcance internacional, en un esfuerzo por coordinar y facilitar un intercambio de información sobre las actividades criminales de los grupos anarquistas de la época. En el Protocolo de San Petersburgo se especificarán tanto los procedimientos para expulsión de anarquistas, como la creación de protocolos para regularizar las comunicaciones inter-policiales.

2. El 6 de septiembre de 1901 el Presidente McKinley fue tiroteado por el anarquista León, falleciendo ocho días después. Czolgosz fue juzgado y condenado a la pena de muerte. Fue electrocutado el 29 de Octubre de 1901.

3. En Estados Unidos, se producirá una represión feroz contra el anarquismo tras el asesinato del Presidente McKinley, La primera legislación en este sentido será la Ley del Estado de Nueva York de 3 de abril del año 1902, seguida de la Ley del Estado de Nueva Jersey en el mismo año (única ley promulgada en Estados Unidos que condena y castiga las conspiraciones anarquistas). Continuará expandiéndose este tipo de legislación en el Estado de lowa, en el Estado de Ohio y en el Estado de Pensilvania, con las leyes de 31 de marzo de 1870 y de 22 de abril de 1900.A partir del año 1908, la mayoría de los defensores de la violencia anarquista o habían muerto o se dedicaban a actividades más pacíficas, la época de los atentados anarquistas dio paso al anarquismo cuyo objetivo será actuar entre las masas de trabajadores.

4. Los diez países firmantes del protocolo de San Petersburgo serán: Alemania, Austria-Hungría, Dinamarca, Suecia, Noruega, Rusia, Rumania, Serbia, Bulgaria y Turquía. 


\section{LA CONFERENCIA INTERNACIONAL DE GINEBRA DEL AÑO 1937 Y LA DEFINICIÓN DE “ACTOS DE TERRORISMO"5}

El impacto creado por el asesinato en Marsella del rey Alejandro de Yugoslavia y del Ministro de Asuntos Exteriores francés Luois Barthou ${ }^{6}$ el día 9 de octubre del año 1934, hará que nuevamente se produzca un impulso de cooperación entre los Estados en la lucha contra la violencia terrorista, ${ }^{7}$ así, el día 10 de diciembre del año 1934 la Sociedad de Naciones dictará una Resolución sobre el fenómeno terrorista: "Es deber de cada Estado no apoyar ni tolerar en su territorio cualquier actividad terrorista con un fin político".

Del día 1 al 16 de noviembre del año 1937, se celebrará en la ciudad de Ginebra, convocada por la Sociedad de las Naciones, la "Convención para la Prevención y la Represión Internacional del terrorismo", dándoselos primeros pasos hacia la adopción de unas medidas normativas de alcance universal contra el terrorismo internacional, que se formularon en el marco de la Sociedad de Naciones" (Calduch, 2001, p. 28).

La convocatoria de la Conferencia de Ginebra de noviembre del año 1937 tendrá como objetivo "realizar una prevención y un castigo más efectivo del terrorismo de carácter internacional". Entre sus resoluciones adoptó dos importantes instrumentos: La Convención para la Prevención y la Represión del terrorismo, y La Convención para la Creación de una Corte Penal internacional, primer antecedente destinado a instaurar una Corte Penal Internacional de carácter permanente.

Ninguna de las dos Convenciones entró en vigor ya que no fueron ratificadas, demostrando la ausencia de una verdadera voluntad política por parte de los Estados para enfrentar el fenómeno del terrorismo.

Es importante destacar que va a ser en la Convención de Ginebra donde vamos a encontrar una definición de actos de terrorismo, definición difícil de encontrar en algún instrumento jurídico,

5. La Convención del año 1937 aparece reflejada en diversos instrumentos internacionales como en el "Informe sobre Terrorismo y Derechos Humanos" de la Comisión Interamericana de Derechos Humanos del 22 de octubre de 2002: "El terrorismo está lejos de ser un fenómeno nuevo; en efecto, podría inclusive decirse que es anterior a la historia registrada. Su tratamiento como materia del derecho internacional es de origen más reciente. Entre los primeros empeños por abordar el terrorismo como materia de preocupación jurídica para la comunidad internacional estuvo la redacción por la Sociedad de las Naciones de la Convención de Ginebra de 1937 para prevenir y sancionar el terrorismo, redactada por la Liga de Naciones, y que nunca entró en vigencia. Posteriormente, las Naciones Unidas adoptaron iniciativas similares contra el terrorismo a través de la negociación de tratados multilaterales y de la labor de los órganos de la ONU a distintos niveles".

6. El 9 de octubre de 1934, Louis Barthou, ministro de Asuntos Exteriores fue encargado de recibir en Marsella al rey Alejandro I de Yugoslavia, fue asesinado al mismo tiempo que el monarca por un terrorista.

7. Muy a menudo, la Comunidad Internacional ha reaccionado emocionalmente a actos terroristas particularmente sangrientos. Así, en el seno de la ONU se han elaborado más de 12 Convenciones entre los años 1969 y 2001. 
ya que ni los expertos en Derecho Internacional ni los representantes de los Gobiernos se han puesto nunca de acuerdo en este sentido.

Para la Convención de Ginebra serán actos de terrorismo los siguientes: "actos criminales contra un Estado o cuya finalidad sea infundir terror a personas individuales, grupos de personas o al público en general" (Revista Internacional de la Cruz Roja. 2002, p. 1).La definición se refiere a actos criminales sin especificar que actos son ilícitos en el contexto del terrorismo, pero fue la primera definición de terrorismo con pretensión de vigencia internacional.

\section{EL IMPACTO EN LAS REGLAMENTACIONES INTERNACIONALES}

El camino seguido por la Comunidad internacional, desde la celebración de la Conferencia de Ginebra de 1937, se ha reflejado en la voluntad de los Estados por avanzar y dar respuestas efectivas ante el problema común del terrorismo, intentado relacionar amenazas con respuestas jurídicas efectivas de alcance internacional.

A lo largo de los dos últimos decenios, en el seno de la ONU se han aprobado tratados que tratan de dar respuesta a aspectos específicos del fenómeno terrorista. Así, podemos destacar como los principales instrumentos universales contra el terrorismo los siguientes:

- Convenio sobre las infracciones y ciertos otros actos cometidos a bordo de las aeronaves ("Convenio de Tokio"), 1963

- Convenio para la represión del apoderamiento ilícito de aeronaves de 16 de diciembre de 1970.

- Convenio para la represión de actos ilícitos contra la seguridad de la aviación civil de 23 de septiembre de 1971.

- $\quad$ Convención para prevenir y sancionar los actos de terrorismo configurados en delitos contra las personas y la extorsión conexa cuando estos tengan trascendencia internacional." Adoptado en Washington D.C. el 2/2/1971 CONF/ASAM/Reunión: Tercer período Extraordinario de Sesiones de la Asamblea general. Registro ONU: 03/20/89 № 24381 Vol.

- Convención sobre la represión y el castigo de delitos contra las personas internacionalmente protegidas inclusive los Agentes Diplomáticos de 14 de diciembre de 1973.

- $\quad$ Convención Internacional contra la toma de rehenes año 1979.

- $\quad$ Convención sobre la protección física de los materiales nucleares, 1980. 
- $\quad$ Protocolo para la represión de actos ilícitos de violencia en los aeropuertos que presten servicio a la aviación civil internacional, 1988.

- $\quad$ Protocolo para la represión de actos ilícitos contra la seguridad de las plataformas fijas emplazadas en la plataforma continental, 1988.

- Convenio para la represión de actos ilícitos contra la seguridad de la navegación marítima, 1988.

- $\quad$ Convenio sobre la marcación de explosivos plásticos para los fines de detección, 1991.

- Convenio Internacional para la represión de los atentados terroristas cometidos con bombas, 1997.

- $\quad$ Convenio Internacional para la represión de la financiación del terrorismo, 1999.

- $\quad$ Enmienda a la Convención sobre la protección física de los materiales nucleares, 2005

- $\quad$ Protocolo para el Convenio para la represión de actos ilícitos contra la seguridad de la navegación marítima, 2005

- $\quad$ Protocolo del Protocolo para la represión de los actos ilícitos contra la seguridad de las plataformas fijas emplazadas en la plataforma continental, 2005

- $\quad$ Convenio Internacional para la represión de los actos de terrorismo nuclear, 2005

- Protocolo Complementario del Convenio para la represión del apoderamiento ilícito de aeronaves, 2010.

- $\quad$ Convenio para la represión de actos ilícitos relacionados con la aviación civil internacional, 2010.

Según el Informe del Grupo Asesor sobre las Naciones Unidas y el Terrorismo, del año 2002 (Asamblea General, ONU, A/57/273-S/2002/875, 2002, p. 2):

En términos generales, las Naciones Unidas deberían propugnar, cumplir y reafirmar los principios y propósitos principales de la Carta de las Naciones Unidas, cuyo núcleo se ve menoscabado y amenazado por el terrorismo. Las actividades de la Organización deberían formar parte de una estrategia tripartita que apoye los esfuerzos mundiales por: a) Disuadir a los grupos de descontentos de adoptar el terrorismo; b) Negar a grupos o individuos los medios para llevar a cabo actos terroristas; c) Fomentar una cooperación internacional amplia en la lucha contra el terrorismo. 
La ampliación y el fomento de la cooperación internacional como estrategia para enfrentar el problema del terrorismo, convierte a la Comunidad Internacional en un actor indispensable para enfrentarse y vencer la amenaza de actores no estatales que emplean una estrategia basada en la violencia y el terror.

\section{CONCLUSIONES}

Las ideas que inspiran el nacimiento del terrorismo moderno no son originales, sí lo son su justificación ideológica y su metodología, que han ido evolucionando a lo largo de la historia moderna. Determinados movimientos y corrientes ideológicas las conceptualizan y las desarrollan, las absorben, para señalar a través de una estrategia política definida, llevar a cabo un ideal transformador radical.

A finales del siglo XIX aparecerá la primera oleada de terrorismo moderno. Una ola sistemática de atentados, vinculados al anarquismo político, se producirán en casi todo el mundo, y cuya actividad se va a dar de manera más evidente en Europa. Diversos grupos anarquistas inician una lucha violenta contra el Estado bajo el lema de "acción directa" o "propaganda por el hecho". La forma de llevar a cabo estos atentados planteará una técnica que fielmente se reproducirá hasta nuestros días.

La estrategia adoptada por el movimiento anarquista y la incapacidad del sistema político para absorber, dar una respuesta, e integrar dentro del sistema a los nuevos grupos sociales y corrientes ideológicas del agitado siglo XIX dará como resultado que el fenómeno terrorista sea uno de los rasgos característicos de este período.

Los estados, pronto comprenderán la necesidad de dar una serie de respuestas legislativas ante el problema común del terrorismo, y entenderán que la cooperación internacional, es un elemento fundamental para combatir y vencer un fenómeno de violencia y de terror que tiene como finalidad superar el modelo social establecido para propiciar posteriormente su sustitución.

El impacto de las primeras respuestas internacionales frente a la amenaza del terrorismo, destacan, no por la efectividad de las medidas o acuerdos alcanzados, si no por la voluntad, el esfuerzo y la determinación de la Comunidad Internacional de dar una respuesta unitaria, de aunar esfuerzos en la lucha antiterrorista y de comenzar a construir un espacio de seguridad en Europa y en el resto del Mundo. 


\section{REFERENCIAS}

- $\quad$ Andrew, M., (1974).The Concept of Power and its use Explaining Asymetric Conflict. Londres:The Richardson InstituteforConflict and Peace Research.

- Aparicio Ordás, L. (2012).Enfrentamientos Asimétricos, la respuesta del Estado Español frente a la amenaza del terrorismo. Asimetría y Simetría en el conflicto. Tesis Doctoral. Madrid: Universidad Alfonso X el Sabio.

- Archivo Ministerio de Asuntos Exteriores de España (AMAE), Madrid, Sección Histórica, Política Exterior.

- $\quad$ Arendt, H. (2008).Sobre la violencia. Madrid: Alianza editorial.

- Asua Batarrita, A. (2002). Concepto jurídico de Terrorismo y Elementos subjetivos de finalidad. Fines políticos últimos y fines de terror instrumental. En Echano Basaldua, J., (coord.), Estudios Jurídicos en Memoria de José María Lidón. Bilbao: Universidad de Deusto. Recuperado de: http://portal.uclm.es/ descargas/ idp_docs/ doctrinas / concepto jurídico de terrorismo\%5B1\%5D \%5B 1\%5D.adelaasua.pdf.

- $\quad$ Avilés Farré, J., y Herrerín López, A., (eds.) (2008).El nacimiento del terrorismo en occidente. Anarquía, Nihilismo y violencia revolucionaria. Madrid: Editorial Siglo.

- Bobbio, N. (1988). Las ideologías y el poder en crisis. Barcelona: Ariel.

- $\quad$ Calduch Cervera, R. (2001). La incidencia de los atentados del 11-S en el terrorismo internacional. Recuperado de: http://eprints.ucm.es/ 6495 /1/ REDI_Calduch.pdf.

- $\quad$ Caro Baroja, J., (1989).Terror y Terrorismo. Madrid: Plaza y Janés.

- Casanova J., (2007).Anarquismo y violencia política en la España de siglo XX. Zaragoza: Institución Fernando el Católico, Diputación de Zaragoza.

- $\quad$ Convention for the Prevention and Punishment of Terrorism, 19 League of nations O.J. 23 (1938).

- González Calleja, E. (1998). La Razón de la fuerza. Orden público, subversión y violencia política en la España de la Restauración (1875-1927). Madrid: CSIC.

- $\quad$ Laqueur W., (2003). La Guerra sin fin. El Terrorismo en el siglo XXI. Barcelona: Destino S.A. 
- $\quad$ Larenz, K. (2001). Metodología de la ciencia del Derecho. Barcelona: Ariel Derecho.

- Morán Blanco, S. (2010). La Unión Europea y la creación de un espacio de segundad y justicia. Visión histórica de la lucha contra el terrorismo internacional en Europa. Anuario Español de Derecho Internacional, 26.

- $\quad$ Rapoport, D.C., (2006).Entonces y ahora: La importancia de los paralelismos. Fundación Manuel Giménez Abad de Estudios Parlamentarios y del Estado Autonómico, Recuperado de: http://www.almendron.com/tribuna/14103/ entonces-y-ahora-la-importancia-olainsignificancia- de-los paralelismos /

- $\quad$ Revista Internacional de la Cruz Roja, Actos de terror, terrorismo y derecho internacional humanitario, № 847, 2002.

- $\quad$ Rivera Beildas, I. y Almeda, E. (2005). Política Criminal y Sistema Penal: Viejas y Nuevas Racionalidades Punitivas. Barcelona: Anthropos. 